\title{
Tejidos y cerámica de China en la gobernación de Tucumán y Buenos Aires, siglo XVIII. Apuntes sobre su circulación y consumo/
}

\author{
Chinese Textile and Ceramic in the Government of Tucumán \\ and Buenos Aires, Eighteenth Century. \\ Notes on its Circulation and Consumption
}

\section{Mariano Bonialian}

Universidad Nacional de Córdoba, Argentina

El ensayo explora el comercio asiático y el consumo de su tejido y cerámica en la gobernación de Tucumán y Buenos Aires en el siglo XVIII. Se analiza el «boom» de los tejidos chinos que ingresaron por Lima hacia el espacio austral entre 1700 y 1740. Por otra parte, se explica el ingreso de loza china por el puerto de Buenos Aires en la segunda mitad del siglo. Finalmente, se reconocen dos oleadas culturales en la región: una primera tendiente a la «europeización» de artículos chinos; y una segunda que implicó la «orientalización» de los productos europeos.

Palabras Claves: Comercio, Consumo, Textiles chinos, Cerámica china, Gobernación de Tucumán, Buenos Aires, Siglo XVIII.

This essay explores the Asian trade and consumption of textile and ceramics in the Government of Tucuman and Buenos Aires in the Eighteenth century. The Chinese textile «boom» that entered from Lima towards the southern space between 1700 and 1740 is analyzed. In second place, the entry of Chinese ceramics through Buenos Aires port in the second half of that century is explained. Finally two culture waves are recognized in the region: the first one tended to an «europeanization» of the Chinese objects; the second one involved the "orientalización» of the european objects.

Keywords: Trade, consumption, Chinese textiles, Chinese ceramics, Tucuman`s Government, Buenos Aires, 18th Century. 


\section{Introducción}

La cultura material de la América colonial se nutrió de objetos venidos de diferentes partes del planeta. Se sabe que el mundo hispanoamericano estuvo permeable a los influjos económicos y culturales del Occidente, pero todavía nos resistimos a revelar lo que serían unas inéditas conexiones con la China imperial. La América colonial generó perdurables lazos económicos con el Oriente, directos o con la mediación europea, resultando un «producto histórico» del que aun los historiadores no alcanzamos a descifrar en su magnitud. Espacios del Orbe indiano como la gobernación de Tucumán y el puerto de Buenos Aires, rincones periféricos del imperio y muy distantes de China, se hallaron influidos por la cultura material del Oriente. El presente ensayo explora de qué manera logró hacerse presente el comercio asiático por la región austral del continente y la cultura consumidora que se configuró en torno a la seda y la cerámica china; los dos rubros orientales de mayor comercialización por Hispanoamérica. Nuestro marco temporal será el siglo XVIII; un período de evidentes cambios tanto en los circuitos de los artículos chinos hacia la región como en el tipo de artículos seleccionados por los consumidores.

La propuesta que presentamos puede resultar original, más teniendo en cuenta el espacio geográfico atendido. Pero la problemática sobre las relaciones económicas entre China e Hispanoamérica goza de una importante tradición historiográfica. Hace tiempo se viene percibiendo los alcances de la conexión entre China y la Nueva España en la cultura económica novohispana, en la que el galeón de Manila tuvo un rol protagónico. ${ }^{1} \mathrm{Si}$ bien desde finales del siglo XVI la legislación peninsular ordenó que los artículos asiáticos comercializados por la nao de China sólo se consumieran en el ámbito novohispano, la realidad demostró que Guatemala, Ecuador y Perú participaron en la contratación asiática. Gran cantidad de estudios confirmaron la extensión de la circulación de bienes chinos hacia el virreinato del Perú. ${ }^{2}$ Pero nada sabemos de su prolongación sobre otras áreas más lejanas, del tipo de artículos orientales comercializados y de su cultura consumidora.

1 De una lista extensa, se destacan: Schurz, 1939; Chaunu, 1960; Yuste, 1984 y 2007; Bernal, 2004. Vale destacar la última aportación ofrecida por diferentes especialistas en Bernabéu y Martínez Shaw, 2013.

2 Schurz, 1918; Borah, 1975; Ramos, 1970; Navarro García, 1965; Flores, 2005; Bonialian, 2012. 
El primer objetivo será demostrar que los tejidos y la loza de China llegaron a plasmarse por una geografía más amplia que la que supone la rada novohispana y peruana. Nos resultaría difícil explicar el éxito de esta contratación por las Indias Occidentales concibiendo a los productos venidos del Oriente como algo exclusivamente exótico, singular y en respuesta a una cultura de consumo elitista. ${ }^{3}$ Desde luego que el consumo suntuoso es una característica válida, fundamentada en los estudios; pero este atributo no podría explicar por sí solo la notable expansión de su consumo por toda la geografía imperial. Nuestro argumento es que la baratura de los artículos chinos, su diversa calidad, los bajos costos de comercialización, como así también un patrón de producción y diseño más familiar y reconocible para un consumo social ampliado se convirtieron en factores fundamentales para que los bienes chinos se irradien por todo el arco continental; desde las islas Filipinas hasta la realidad más austral del continente.

El trabajo consta de cuatro apartados. En un inicio advertimos sobre las fuentes y la metodología propuesta. En el segundo apartado se estudia la notable circulación y consumo de sedas y tejidos chinos por la gobernación de Tucumán, particularmente por la ciudad de Córdoba entre 1700 y 1740. Se identificarán las vías comerciales de su ingreso y qué consumidores accedieron a ellas. En el tercer apartado analizamos el caso de la cerámica y loza de China por Buenos Aires durante la segunda mitad del siglo. Aquí también se explorará la vía de su importación y el público que las utilizó. En la última sección se exploran los aspectos culturales de este consumo. Allí se analizará el tipo de mezcla de tradiciones europeas y orientales con que los bienes fueron presentados al consumidor, a partir de dos oleadas que configuraron la cultura material por la región. La primera, titulada como «occidentalizando lo oriental», daría cuenta de un proceso de «europeización» de artículos procedentes de China. La segunda corriente, identificada bajo el rótulo de lo chinesco, nos asoma a las lógicas de intervención de los artículos occidentales con vistas a su «orientalización».

3 Sobre el consumo suntuario de los objetos venidos del Oriente, véase para el caso de la Nueva España: Curiel, 1992 y Bonta de la Pezuela, 2008; para el Perú: Kuwayama, 2000-01; para el Río de la Plata: Porro, Astiz y Rospide, 1982 y Porro y Barbero, 1994. 


\section{Fuentes y metodología}

¿Qué tipo de fuentes nos ayudarían a identificar los bienes asiáticos existentes por la gobernación de Tucumán y Buenos Aires cuando sabemos que hasta el último cuarto del siglo XVIII la legislación española prohibió su intercambio y consumo ${ }^{4}$ Esta singular característica hace que los registros oficiales no logren registrarlos. Son los protocolos notariales (cartas dotales, inventarios post-mortem, sucesiones, testamentos, comerciales y bienes patrimoniales) las fuentes que nos permiten superar el este inconveniente. Y ello se debe a la simple razón de que los protocolos notariales no discriminaron los bienes autorizados de los ilegales. El notario no sólo alcanza a nombrar todos los bienes que tenía en su poder una persona o familia, sino que ofreció información detallada sobre ellos (estado, valor, composición, etc.).

Consultamos más de 400 protocolos, de los cuales 181 contienen telas y cerámicas chinas. De esos 181, 112 se refieren a la gobernación de Tucumán y 69 a Buenos Aires. Por lo tanto, en un $45 \%$ de las fuentes revisadas se encontraron bienes chinos. Podría pensarse que es un número relativamente escaso para un estudio que contempla 100 años. Sin embargo, estamos convencidos que es una cantidad suficiente para aproximarnos a un escenario histórico de una problemática prácticamente desconocida. Nuestro plan fue consultar un número equitativo de expedientes y valorizar cada época del siglo con la misma atención. En este sentido, se llegaron a revisar 20 protocolos para cada década y espacio. Como se expresa en el Cuadro 1, la revisión de los primeros 30 años fue todo un éxito, puesto que en casi todos los expedientes de la gobernación de Tucumán aparece algún bien de la China, en particular textil. Para la segunda mitad del siglo, el número de protocolos que contienen objetos chinos es menor, aunque ello, como veremos, no implica que la cantidad de bienes que circularon y se consumieron en ese período por el territorio haya sido menor.

Lo que sí valdría reconocer es que los inventarios post-mortem, testamentos y sucesiones, agrupados en la columna (1) del cuadro, fueron las fuentes más consultadas; le siguen las cartas dotales y bienes patrimoniales (2) y, en tercer lugar, los inventarios de tienda, concurso de acreedores y embargos (3). En esas columnas, divididas por década, contabilizamos el

4 Desde 1604, el Consejo de Indias decidió prohibir el movimiento de bienes asiáticos desde el puerto de Acapulco hacia El Callao. El Perú y todo el espacio sudamericano quedaban así marginados de la contratación asiática. Véase al respecto: Archivo General de Indias (AGI), Filipinas, 1, núm. 66, 15-17. Consultas sobre la contratación de Filipinas, 13 de noviembre de 1604. 
número el número de protocolos donde encontramos presencia de bienes chinos. Estas fuentes están ubicadas, en su gran mayoría, en el Archivo Histórico de la Provincia de Córdoba (AHPC) y en el Archivo General de la Nación Argentina de la ciudad de Buenos Aires (AGN). Del archivo de Córdoba sobresalen los ramos Escribanía y Protocolos y del segundo archivo cobra especial relieve el de Sucesiones. Si bien creemos que esta metodología es la forma más adecuada para analizar nuestro objetivo, vale reconocer sus limitaciones y obstáculos. En general, los protocolos notariales se realizaron sobre personas y familias ricas, lo que nos impide acercarnos de primera mano a las características de consumo de artículos chinos en las capas sociales medias y bajas. Aun con esta limitación, el trabajo no renunciará a abordar el problema. En segundo lugar, se piensa con acierto que los bienes contenidos en los protocolos notariales eran viejos y en mal estado, por lo que sus valores no estarían reflejando precios de mercado. Teniendo en cuenta esta observación, vale señalar que la mayoría de los bienes chinos que aparecen en los protocolos se consideran «nuevos» 0 «a la moda», por lo que sus valores no estarían tan lejanos al valor real. Una última advertencia: el cuadro 2 con su soporte documental que aparece más adelante será el punto de partida de nuestras reflexiones e hipótesis.

CUADRO 1

PROTOCOLOS NOTARIALES CONSULTADOS

\begin{tabular}{|c|r|r|r|r|r|r|r|r|}
\hline & \multicolumn{4}{|c|}{ Gobernación de Tucumán } & \multicolumn{5}{|c|}{ Buenos Aires } \\
\cline { 2 - 9 } Décadas & 1 & 2 & 3 & Total & 1 & 2 & 3 & Total \\
\hline $1700-09$ & 14 & 5 & 1 & 20 & 8 & 2 & & 10 \\
\hline $1710-19$ & 16 & 11 & & 27 & 10 & & & 10 \\
\hline $1720-29$ & 13 & 3 & 2 & 18 & 4 & 1 & & 5 \\
\hline $1730-39$ & 4 & 3 & 1 & 8 & 7 & & 4 & 11 \\
\hline $1740-49$ & 4 & 2 & & 6 & 2 & 1 & 1 & 4 \\
\hline $1750-59$ & 5 & & 1 & 6 & 3 & & 1 & 4 \\
\hline $1760-69$ & 3 & & & 3 & 2 & & & 2 \\
\hline $1770-79$ & 4 & 1 & 2 & 7 & 4 & & 1 & 5 \\
\hline $1780-89$ & 6 & 2 & & 8 & 6 & 3 & & 9 \\
\hline $1790-99$ & 5 & 2 & 2 & 9 & 7 & 2 & & 9 \\
\hline Total & 74 & 29 & 9 & 112 & 53 & 9 & 7 & 69 \\
\hline
\end{tabular}

Referencias: 1. Inventarios post-mortem, testamentos y sucesiones. 2. Cartas dotales y bienes patrimoniales. 3. Inventario de tienda, concurso de acreedores y embargo. 


\section{Sedas y tejidos de China desde Acapulco hasta la gobernación de Tucumán}

Si el objetivo consiste en explorar ese desconocido mundo del comercio y consumo de sedas y loza de China por la gobernación de Tucumán y Buenos Aires habría que referirse, desde un inicio, a los cambios registrados por los grandes circuitos del imperio durante el transcurso del siglo XVIII. Todavía en las primeras décadas del siglo XVIII la gobernación de Tucumán y Buenos Aires continuaban manteniendo una relación de dependencia con el eje de Lima, el cual respondía a la fuente de abastecimiento de Portobelo. ${ }^{5}$ Sin embargo, esta orientación no habría sido la única vía importadora de mercancías extranjeras hacia el espacio sudamericano. A la par del eje España-Portobelo-Lima-Charcas-Buenos Aires, actuaba, desde finales del siglo XVI, el eje mercantil del Pacífico.

$\mathrm{Al}$ menos desde 1680, el virreinato de la Nueva España, luego de responder al consumo de sus mercados internos, almacenaba una gran cantidad de bienes asiáticos y europeos con el fin de reexpedirlos por el mar del Sur hacia el puerto de El Callao. ${ }^{6}$ Llegados a Lima y luego de responder a la demanda de las plazas andinas, la canasta de artículos extranjeros se movilizaba hacia las ciudades de Salta, Tucumán y Córdoba. Las sedas y los textiles de China que ingresaron a las ciudades de la Audiencia de Charcas y aun al Río de la Plata provinieron de Lima, desde México, y fueron el resultado del movimiento en escalas en su dirección norte-sur. En Lima, el eje del Pacífico se conectaba con la vía de Portobelo y, desde allí, los objetos orientales se movilizaban junto a una variada canasta de productos europeos, novohispanos, centroamericanos y peruanos y de la tierra hacia Salta, Catamarca, Tucumán, Córdoba y Buenos Aires. Vemos así la conformación de un eje mercantil oculto que fue desde el occidente novohispano hasta el puerto atlántico de Buenos Aires. Si bien nuestro estudio contempla el siglo XVIII, se podría decir que la circulación y consumo de tejidos asiáticos, en particular de la seda, por la región austral funcionaba, con alta y bajas en su intensidad, desde finales del siglo XVI.

La seda china llegó a ser muy estimada en los mercados hispanoamericanos. Sus calidades diversas y su baratura habrían puesto en jaque al comercio ultramarino peninsular que, apenas iniciado el siglo, mostraban

5 Céspedes, 1947, 34-35.

6 Bonialian, 2012. 
unos pobres negocios en las ferias de Jalapa y ciudad de México. Los comerciantes peninsulares decían que la disminución en los intercambios por el Atlántico se debía al éxito competitivo del consumo de sedas chinas. ${ }^{7}$ El Consejo de Indias afrontó el problema y con la intención de proteger los textiles de fabricación española y europea, decidió en el año 1718 prohibir el ingreso de la seda china hacia la Nueva España. El virrey novohispano, marqués de Valero, desconoció la normativa al considerar que los tejidos chinos eran de «regular vestuario», con «precio muy acomodado y porque la mayor parte del reino deseaba la nao de China con sus telas que el arribo de la flota española», la cual ofertaba sus tejidos a un precio mayor. ${ }^{8}$ Las referencias al consumo masivo y diverso de las telas chinas abundan. Hacia mitad del siglo, el virrey novohispano Revillagigedo advertía que «el comercio de Filipinas es aclamado en este reino porque suministra a la gente pobre del país», por él «trafica el de poco caudal, el de mediano y mayor; y es recíprocamente común en el consumo pues le gasta desde el pobre, el mediano, el rico y de mayor caudal». ${ }^{9}$ Estamos en presencia de un conjunto de afirmaciones contundentes brindadas por los máximos funcionarios coloniales y que, como se verá enseguida, se corresponden muy bien con la información que contienen los inventarios de la gobernación de Tucumán y Buenos Aires. Habría sido tan elevada la importación de seda oriental a la Ciudad de los Reyes procedente de la Nueva España que su saldo positivo, el excedente de mercaderías, se reexpidió hacia Charcas y los mercados más australes. En otros términos, el eje del Pacífico en el cual Lima fue uno de los puntos redistribuidores más importante tuvo una gran responsabilidad para crear un boom del consumo de ropa de China por la gobernación del Tucumán. ${ }^{10}$ Vale reseñar un caso particular que pone a la luz el funcionamiento del eje y el movimiento de las telas chinas desde Lima hacia Córdoba.

En los años iniciales del siglo XVIII, Juan de Buitrón, un acaudalado mercader peninsular instalado en la ciudad de Córdoba, viajó hacia Cuzco con la intención de comprar tejidos extranjeros para luego venderlos por las plazas consumidoras de Salta, Tucumán y Córdoba. Llevaba consigo más

7 Álvarez de Abreu, 1977, I, 130-234.

8 AGI, Filipinas, 206, núm. 1, 823-826.

9 Álvarez de Abreu, 1977, I, 82.

10 Entre 1700 y 1720 numerosas embarcaciones francesas lograron arribar a los puertos del Pacífico chileno y peruano procedentes de Filipinas y Cantón. La tela asiática desembarcada en esos puertos habría llegado también a la gobernación de Tucumán. Véase al respecto: Malamud, 1986, 48-60; Bonialian, 2012, 230-245. 
de 3 mil mulas; forma de pago muy utilizada en las economías regionales del espacio. En 1713, ya en el Perú, Buitrón fallece. Manuela de Liendo, quien había sido esposa de Buitrón y con quien tuvo una hija llamada Josefina, solicitó por medio de juicio sucesorio el envío de los bienes que hasta ese momento el mercader tenía almacenado en el Cuzco. ${ }^{11}$ Vale conocer la notable cantidad de telas y tejidos de China que aparecen en el envío despachado desde Potosí hacia Córdoba:

2 calzones de felpa musgo de la China con encaje de oro; 1 sobrecama de damasco carmesí de la China forrada en saya saya; 12 libras de seda china; 51 libras de seda musga de la China; 3 piezas de damascos carmesíes de la China; 2 piezas de otros damascos de la China blanco; 9 piezas de rasos labrados de colores de la China; 12 libras de raso musgo labrados de la China; 11 libras de brocato de la China; 9 libras de raso labrado de la China; 2 libras de Jerga de la China; 1 pieza de brocato carmesí azul y verde con flores de oro de la China; 2 piezas de gorgoranes musgos de la China; 5 atados de saya sayas de diferentes colores de la China ; 12 piezas de rasos llanos de la China; 10 piezas de gorgoranes musgos de la China; 9 piezas de gurbiones musgos de la China; 1 pieza de raso musgo de la China labrado; 2 piezas de seda de la China; 102 docenas de peines ordinarios del Cuzco y de la China; 1 pieza de telas ordinarias de la China; dos escritorios de Cajamarca aforrados con musgo de la China; 1 par de medias usadas de musgo de la China; 60 piezas de cintas de la China; 10 piezas de pequines de la China; 2 pares de calzones de la China; 51 libras de estameña de seda de musgo de la China; 4 libras de brocato verde de la China; 4 piezas de rasos a flores de la China; 3 piezas de capicholas de la China; 24 varas de capichola color ámbar de la China. ${ }^{12}$

El caso Buitrón resulta una fiel expresión del cuadro 2 reproducido más adelante. En los protocolos de la gobernación de Tucumán aparecen telas en varas, listas para su confección, o tejidos manufacturados para el vestir o para el hogar. Otras telas orientales que se consumían eran el raso y tafetán de seda, damasco, jerga, saia, gorgorán, gurbión, capichola, estameña, angaripola, muselina, lienzo, holandilla, calamaco, damasquillo y el camellón. Las hubo para todos los gustos, de finísima calidad hasta la más ordinaria, que se expresan con los siguientes calificativos: fina elaboración, a la moda o, por el contrario, ordinaria y de segunda calidad. Con esta variedad de telas se elaboraron pequines, armadores, chupas, hongarinas, capotes, calzones, polleras, capas o rebozos, sobretodos, delantales, medias, batas, birretes o gorros, pañuelos, tapapiés, camisas o casacas, ceñidores

11 Archivo Histórico de la Provincia de Córdoba (AHPC), Escribanía 1, año 1719, 241, exp. 9,171 .

12 Ibidem, 188-193. 
y sotanas. Para decorar o de uso práctico del hogar se confeccionaban, ya sea en los obrajes asiáticos o en los locales, cortinas, colchas, sobrecamas, cielos de altar, fundas, cojines, sábanas, manteles, mantas, doseles para iglesias, bolsas, apretadores, alfombras, pabellones y colgaduras. Como podremos ver en las páginas siguientes, la vara de algunas sedas y telas llegadas de China llegaron a tener un valor inferior a la manufactura local, la llamada ropa de la tierra, que por las primeras décadas del siglo acusaban precios iguales o más elevados. ${ }^{13}$

No hay duda que los tejidos compuestos con fina seda del Oriente fueron un componente distintivo del consumo de elite. Existieron tejidos que incluso podían superar con creces el valor de similares piezas europeas. Los inventarios arrojan muchísimos casos. Josefa Savina Villamonte, doncella de rica familia de la ciudad de Córdoba, recibió en su dote de 1717 dos sobrecamas: una «grande de la china bordada con hilo de oro y flecadura $[s i c]$ de lo mismo» y otra sobrecama de Inglaterra. La primera se cotizaba en la notable suma de 280 pesos, el valor que por esos años valía un esclavo; mientras que la segunda se valuó en 50 pesos, menos del cuarto del valor de la primera. ${ }^{14}$ Juan José Campero, marqués del Valle de Tojo de Jujuy, contó en su extenso inventario con «una camisa de brocato nácar de alta cuenta, nueva, forrada en fino raso chino a flores de 230 pesos». ${ }^{15}$

Los inventarios consultados muestran que el término «moda» estaba fuertemente asociado al textil chino. Se lo añadía cuando se referían a vestidos de Pequín, casacas de China o incluso al raso de seda de China usados por capitanes, maestres y doncellas. A pesar de su ilegalidad, muchos vestidos con tela china ofrecían una identificación de clase, una regla general que cohesionaba a las clases altas. Además del uso de vestimenta, los tejidos de China se utilizaban y se exponían como decorados en los hogares y en los espacios públicos, hasta el punto de decorar los carruajes: muchos capitanes y eclesiásticos los aforraban con cortinas y flocaduras de seda china. ${ }^{16}$ No existen dudas sobre el consumo de fina seda china en los círculos sociales de elite; un mercado que habría complementado — no tanto competido - con la manufactura europea. La legislación española

13 Salas de Coloma, 1998, II, 380-382.

14 AHPC, Ramo Protocolo, Registro 1, 100, 227.

15 Schenone, Gori, Barbieri, 1991, Apéndice, 426.

16 Véase el caso del chantre de la Catedral de Córdoba Bazán de Pedrás Gil (1716), AHPC, Escribanía 1, 1723, 248, exp. 1, 6; y del capitán José Cabrera de Velasco en la ciudad de Córdoba, AHPC, Escribanía 1, 232, exp. 2, 9-10. 
prohibió a los grupos de mediana y baja condición el uso de plata, oro, prendas de seda y otros artículos de lujo. En Córdoba, de hecho, se sancionó a mulatos y mestizos por usar atuendos suntuosos en público. ${ }^{17}$ Pero nuestro propósito es superar la mirada excluyente que el consumo de seda china sólo se comprimió a una esfera de elite, a lo suntuoso o extravagante. En las primeras décadas del siglo XVIII, su consumo superó ese círculo social porque los vecinos comunes, que no pertenecían a los grupos de privilegio, accedieron al textil. El interés de la plebe por los tejidos chinos no se explicaría por una representación cultural en la carrera hacia el ascenso social. Las razones resultaron ser más concretas. Los sectores sociales de medianos y bajos ingresos disponían de textiles asiáticos baratos, de mediana u ordinaria calidad y adaptados para sus necesidades. Hacia la primera década del siglo, el Consulado de Lima definía a la ropa de la China como barata, ordinaria y vulgar, lo que era imposible «ponderar los millones de pesos que han salido de este Reino en retorno de tan vulgares géneros». ${ }^{18}$ Para el caso geográfico que aquí se atiende, los inventarios manifiestan que el consumo amplio y cotidiano de la tela china alcanzaba las áreas rurales del espacio de Tucumán y Buenos Aires, como San Antonio de Totoral, el valle de Ischilín y Domingo del Corral; zonas aledañas a la ciudad de Córdoba ${ }^{19}$ El bajo precio fue un requisito para que las familias rurales puedan acceder al artículo. Aunado a los bajos costos de producción de la seda, su valor se veía abaratado porque se comercializó a través de la vía del contrabando, esquivando impuestos. Más aún, en numerosas ocasiones los barcos llegados al puerto de El Callao desde las costas occidentales de la Nueva España sufrían el comiso de la seda china por ser un bien prohibido, pero luego de negociaciones y bajo el guiño cómplice de las autoridades portuarias, los mercaderes del Perú lograban ingresarla bajo remates y subastas a un menor precio del que regía en el mercado. ${ }^{20}$ Sin embargo, el argumento que nos puede convencer de su bajo valor, se obtiene al

17 Concolorcorvo, 1946, 58-59.

18 Moreyra, 1956, I, 14.

19 En 1708, el señor Antonio Márquez, residente en San Antonio de Totoral poseía en su inventario 10 varas de raso de la China de colores» (1708), AHPC, Ramo Escribanía 1, 218, exp. 4, 3. En el inventario de Francisco de Cornejo de 1711, residente en el valle de Ischilín, figuraba «una camisa a raso ordinario de China», AHPC, Escribanía 1, 227, exp. 3, 3-4. Por su parte, en el inventario de tienda de 1724 de José Lobatón, del pueblo Domingo de Corral, aparecía «2 piezas de cintas de Asia averiadas» y más de 40 varas de angaripolas y muselinas de China», AHPC, Escribanía 1, 251, exp. 3, 1-319.

20 Bonialian, 2012, 308-331. 
cotejar los precios de las telas de fabricación local, los de procedencia europea y los de China que aparecen en los inventarios. ${ }^{21}$ Habría que reconocer, en un inicio, las limitaciones de esta metodología. Por la naturaleza de la información de los inventarios resulta imposible construir una serie de precios. No debemos olvidar que estamos en presencia de bienes ilegales que sortean cualquier control y cuantificación.

En la carta dotal de 1705 de la doncella Ana Pacheco, hija del capitán Juan de Pacheco residente en la ciudad de Córdoba, se valuó una pollera de raso de la China carmesí a 24 pesos, mientras que idéntica prenda compuesta en seda de Granada alcanzaba el triple de valor: 90 pesos..$^{22}$ Por esos años, una «negra libre» de la misma ciudad llamada Micaela, cuyo patrimonio total no superaba los 540 pesos, tenía entre sus escasas prendas «una pollera de raso de la China forrada en sarguilla» cuyo valor llegaba tan sólo a los 2 pesos. ${ }^{23} \mathrm{El}$ ejemplo es notable porque expresa que la ropa compuesta de tela China llegaba incluso a los grupos más bajos de la escala social. En los autos por fallecimiento de 1720 de Pedro Constanza, vecino que era de Buenos Aires, se cotizó la «vara de tafetán chino ordinario» a 4 reales cuando, según los datos de Arcondo, la bayeta y el lienzo - dos tipos de telas producidos en los obrajes jesuíticos de la ciudad de Córdoba y de consumo entre indios, negros y mestizos - rondaban los 8 y 7,7 reales la vara. ${ }^{24} \mathrm{La}$ vara de Cordellate, tela de gran consumo en la región de Tucumán y Buenos Aires y fabricada también en Córdoba para la confección de ropa interior, alcanzaba los 8 reales en 1732, el mismo valor que en esos años estaría costando la vara de raso chino de razonable calidad, no ordinario, en la ciudad de Catamarca de la gobernación de Tucumán. ${ }^{25}$ Más evidencias. En 1768, un conjunto de soldados españoles viajaban desde Buenos Aires hacia Santiago del Estero consumiendo pañuelos de seda chinos, accesorio fundamental para la higiene y la limpieza del sudor y rostro. ${ }^{26}$ Un año después, en 1769 , un prebendado explicaba sobre lo que precisa una persona de su condición para «vivir dignamente». Decía que 30 o 40 pesos valían los manteles más finos reservados «para aquellos días

21 Para el caso de la ciudad de Córdoba: Arcondo, 1992, 270-290.

22 AHPC, Protocolo, Registro 1, 98, s/n de f.

23 Ibidem, 136v.

24 Archivo General de la Nación Argentina (AGN), Ramo Sucesiones, 5335, s/n de exp., 38; Arcondo, 1992, 279-283.

25 AGN, Ramo Sucesiones, 3859, exp. 7, 22.

26 AGN, Ramo Sucesiones, 6726, s/n de exp., 24-32. 
extraordinarios en que convida algún amigo» y que los «manteles comunes» oscilaban los 20 pesos. En esos años en la tienda de un tal Chávez se adquiría un mantel de los llamados «manteles de China» con 10 servilletas a 16 pesos; muy por debajo de los «manteles comunes» y prácticamente el tercio del valor de los manteles ricos. ${ }^{27}$ En definitiva, todos los casos mencionados ilustran el abanico de telas chinas disponibles para su consumo y que contemplan desde el capitán o la doncella pasando por el vecino común, el soldado y aún al esclavo.

\section{CuAdro 2}

SEDAS, TEJIDOS Y LOZA DE CHINA POR LA GOBERNACIÓN DE TUCUMÁN Y BUENOS AIRES, SIGLO XVIII

\begin{tabular}{|c|c|c|c|c|c|c|c|c|}
\hline \multirow{3}{*}{ Décadas } & \multicolumn{4}{|c|}{ Córdoba y Jurisdicción del Tucumán } & \multicolumn{4}{|c|}{ Buenos Aires } \\
\hline & \multicolumn{3}{|c|}{ textiles } & \multirow{2}{*}{ loza } & \multicolumn{3}{|c|}{ textiles } & \multirow{2}{*}{ loza } \\
\hline & elaborados & Bruto/piezas & total & & elaborados & Bruto/piezas & total & \\
\hline 1700-09 & 54 & 105 & 159 & - & 13 & 60 & 73 & 13 \\
\hline 1710-19 & 81 & 294 & 375 & - & 18 & 21 & 39 & 2 \\
\hline $1720-29$ & 42 & 85 & 127 & - & 3 & 10 & 13 & 17 \\
\hline $1730-39$ & 15 & 5 & 20 & - & 8 & 172 & 180 & 20 \\
\hline $1740-49$ & 16 & 16 & 32 & - & 4 & 1 & 5 & - \\
\hline $1750-59$ & 7 & - & 7 & - & - & 10 & 10 & 62 \\
\hline $1760-69$ & 2 & 4 & 6 & 17 & 1 & - & 1 & 15 \\
\hline $1770-79$ & - & 3 & 3 & 11 & 5 & - & 5 & 190 \\
\hline 1780-89 & - & 11 & 11 & 26 & - & - & - & 99 \\
\hline $1790-99$ & 3 & - & 3 & 5 & 3 & - & 3 & 235 \\
\hline
\end{tabular}

Fuentes: En el caso de la gobernación de Tucumán. AHPC, Año 1702, Escribanía 1, 202, exp. 9, 11; 1703, 206, 8, 10; 1702, 205, 1, 4; 1703, 206, 6, 13-14; 1708, 219, 3, 3-35; AHPC, Año 1704-05, Protocolo, Registro 1, inventario 98, s/n de fs.; 1704-05, 1, 98, s/n de fs.; 1704-05, 1, 98, 233-234; 1704-05, 1, 98, s/n de fs.; 1705, Escribanía 1, 209, exp. 4, 56-58; 1706, Protocolo, Registro 1, inventario 99, 67v., 1707, 100, 106; 1707, Escribanía 1, 215, exp. 1, 5-6; 1708, 218, 4, 3; 1708, 1710, 226, 2, $286 ; 1709,220,5,32 ; 1732,268,1,65 ; 1709,222,2,1-2 ; 1710,223,1,100 ; 1710,225,4,5-11 ; 1710-$ 11, Protocolo, Registro 1,inventario 103, 83; 1710-11, 1, 103, 98; 1710-11, 1, 103, 152; 1710-11, 1, 103, 72; 1710, Escribanía 1, 226, exp. 1, 100; 1711, Escribanía 2, 13, 1, 40-43; 1711, Escribanía 1, 227, 3, 3-4; 1711-12, Protocolo, Registro 1, inventario 104, 38-42; 1712, Escribanía 1, 229, exp. 2, 6r.; 1713, 231, 7, 8-14; 1713, 232, 2, 9-10; 1713-14, Ramo Protocolo, Registro 1, inventario 105, 73; 1714, 1, 105, 306; 1715, Protocolo, Registro 1, inventario 107, año 1715-16, 28v.; 1715, 1, 107, 1715-16, 401; 1715, Escribanía 1, año 1730, 264, exp. 3, 188-230; 1716, 238, 1, 4; 1716, 238, 3, 7-9; 1716, 238, 8, 15v.; 1717, 239, 4, s/n de; 1717-18, Protocolo, Registro 1, inventario 108, 92; 1717-18, 108, 26;

27 Probst, 1941, 438; Porro, Astiz y Rospide, 1982, I, 438. 


\section{TEJIDOS Y CERÁMICA DE CHINA EN LA GOBERNACIÓN DE TUCUMÁN}

1723-26, 111, 227; 1717-18, 109, 196-97; 1718, Escribanía 1, año 1720, 244, exp. 7, 76; 1718, 240, exp. 9, s/n de f.; 1718, Schenone, Gori, Barbieri, 1991, 424-429; 1719, Escribanía 1, 242, exp. 9, s/n de fs.; 1721, 246, 6, s/n de f.; 1721, 246, 7, s/n de f.; Escribanía 2, 1724, 16, 14, 10; Protocolo, Registro 1, inventario 111, año 1723-26, 225v.; Escribanía 1, 1724, 251, 3, 1-319; 1724, 250, 9, 35-36; 1724, 251, 4 s/n de f.; 1724-26, Protocolo, Registro 1, Inventario 112, 250; 1726, Escribanía 1, 255, exp. 6, 8; 1734, 276, 2, 42v.; 1737, 280, 2, 7: 1724, 251, 3, 131-133; 1727, 258, 2, s/n de f.; 1731, 267, 3, 4; 1733, AHPC, Escribanía 1, 272, exp. 1, 24 v.; 1733, Protocolo, Registro 1, inventario 119, 23; 1734, 120 , 235; 1734, Escribanía 1, 275, exp. 2, 31 v.; 1737, 282, 4, 5; 1743, Protocolo, Registro 1, inventario 126, 69; Escribanía 1, año 1761, 343, exp. 1, 10-12; 1748, Protocolo, Registro 1, inventario 131, 278: 1749, Escribanía 1, 307, exp. 1, 2-3; 1750, 310, 15, 12; 1756, 324, 1, 48; 1752, 315, 8, 267-292; 1752, 512, 2,$25 ; 1752,512,4,25 ; 1758,334,1,5 ; 1764$, AMC, Actas Capitulares, rollo 16, tomo XXXII, 100-106; 1769, Ramo Escribanía 1, 365, 4, 4-5; 1774, 379, 2, 44; 1777, 387, 1, 3 y 10; 1784-85, 402, 7, 270; 1779, 391, 5, s/n de fs.; 1789, 408, 5, 89; Solá, 1957, 63; 1786, 404, 3, 31; 1786, 405, 8, 11; 1788, 407, 5, 10; 1790, 411, 6, 6-8r.; 1791, 415, 5, 18; 1794, 424, 2, 3; 1793, 418, 11, 304; 1794, 423, 2, 10-135; $1798-99,428,10,10 \mathrm{v}$.

En el caso de Buenos Aires: AGN, año 1690, Ramos Sucesiones, 5671, exp. 12, 151; 1695 , 7700, s/n de exp., 22-25; 1696, 7700, exp. 31, 19v; 1697, 7369, exp. 1, 12; 1700, 3909, s/n de exp., 87v.; 1700, 4309, s/n de exp., 87-89; 1702, 4299, s/n de exp., 29v; 1703, 6369, s/n de exp., 21 v.; 1704 , 3857 , s/n de exp., 14v-17; 1704, 5868, exp. 11, 15; 1707, 4300, s/n de exp., 3v-10; 1708, 7701, s/n de exp., 17-18; 1709, 6246, exp. 3, 40-42; 1712, 5868, 2; AHPC, Escribanía 1, 234, exp. 15, 4 y Protocolo, Registro 1, inventario 106, 306; 1715, 5868, s/n de exp., 18; AHPC, Escribanía 1, 1723, 248, 1, 6; 1716, 5868, s/n de exp., 18v.; 1719, 6263, s/n de exp., 28; 1719, 5558, s/n de exp., 100-102; 1719, 8409, s/n de exp., 351; 1720, 5335, s/n de exp., 38v.; 1723, 5671, s/n de exp., 5r; 1726, 8409, s/n de exp., 37v; 1730, Contrabando y comisos, exp. 5, 2; 1730, Sucesiones, 6720, s/n de exp., 87; 1731, 5336, exp. 6 , 20; 1731, 7701, s/n de exp., 52v; 1731, 6367, s/n de exp., 2; 1733, 5336, 13; 1734, 7369, s/n de exp., 4; 1739, 4301, s/n de exp., 16-18; 1739, 8121, s/n de exp., 150r-v; 1743, 8410, s/n de exp., 4-38; 1744, 5671, s/n de exp., 44; 1748, 5346, s/n de exp., 1v; 1749, 4302, exp. 5, 15v; 1751, 4302, s/n de exp., 36v; 1751, 8410, exp. 19, 9-10; 1756, Bienes de Difuntos, 15-04-07, exp. 4, 8v-52; 1759, Sucesiones, 5672, s/n de exp., 20; 1760, 4303, s/n de exp., 9; 1759-63, 1770, 4309, exp. 7, 3-4; 1772, 5339, s/n de exp., s/n de fs., 1774, 5563, s/n de exp., 104; 1774, 5673, s/n de exp., 13-234; 1777, 6725, s/n de exp., 32; 1780, Porro, 1982, 1, 32-33; 178(i?), 5560, exp. 3, 175; 1782, 7773, 1, 84; 1783, 7773, 3, 102; 1790, 3866, exp. 10, 38-57; 1790, 6727, s/n de exp., 67v.; 1791, 6727, s/n de exp., 4-8; 1792, 5561, s/n de exp., 38; 1793, 5562, exp. 4, 95; 1793, 5674, s/n de exp. 81-82; 1795, 7707, s/n de exp., 16.

Ahora bien, parte de la explicación sobre la presencia de tejidos chinos disponibles para un público consumidor amplio y diverso se encontraría en el tipo de producción y desarrollo de la manufactura local. Habría que señalar que la seda fue - junto con el lino - uno de las materias primas que Perú no llegó a producir. ${ }^{28}$ Esta carencia llevó a alentar la importación de la producida en Europa como de la China. Pero la primera era cara y reservada a los sectores más pudientes. La segunda, de gran variedad en sus precios y calidades, contempló a sectores sociales más amplios y diversos lo que llevaba a estimular mucho más su entrada a la región. Con respecto a la evolución general de la manufactura local, recordemos que,

28 Assadourian, 1982, 131-221. 
según Salas de Coloma, la producción textil del Perú, particularmente los obrajes de Huamanga, acusaban un ciclo de crecimiento en la primera mitad del siglo. Mucho tenía que ver en eso las fallas que vivía el tráfico trasatlántico de Portobelo. Considerando los primeros cincuenta años del siglo, la feria de Portobelo sólo pudo realizarse en tres oportunidades: 1696, 1707 y 1726. Esta presencia tan espaciada no hizo más que disminuir las importaciones de tejidos europeos, provocando el desabastecimiento por el Perú; escasez que a la vez elevó los precios de las telas locales. ${ }^{29}$ En este sentido, es posible suponer que el aumento de los precios de los productos locales, de su incapacidad por suministrar textiles baratos a las plazas consumidoras de la región y las dificultades de contar con el textil europeo dada la crisis del sistema oficial de comercio, la seda china junto con otros tejidos del Oriente adquirieron mayor participación tanto en el mercado masivo como en el de elite.

\section{Desde España hasta Buenos Aires: el caso de la cerámica china (1750-1800)}

Desde 1740 la orientación del espacio sudamericano hacia el Pacífico disminuyó y las economías regionales más australes se inclinaron con mayor fuerza hacia el puerto atlántico de Buenos Aires. La crisis de Lima como punto distribuidor de mercancías fue fruto, en gran medida, de la decadencia de los dos ejes mercantiles mencionados: el oficial de Portobelo-Lima y el ilegal del Pacífico que unía al puerto de Acapulco con el surgidero de El Callao. Como los trabajos de Moutoukias lo demuestran, el puerto de Buenos Aires venía adquiriendo una significativa actividad mercantil - por medio del contrabando o por navíos de permiso- al menos desde mediados del siglo XVII. ${ }^{30}$ Sin embargo, el papel del puerto atlántico como punto importador de mercaderías extranjeras, como depósito para abastecer a las economías del interior cuestionando la función de Lima, llegará con fuerza recién en la segunda mitad del siglo XVIII. ${ }^{31}$ En este contexto, la cerámica originaria de China o su imitación europea tomarán un rol protagónico. El ingreso de la loza se hará por la vía atlántica

29 Salas de Coloma, 1998, II, 380-386.

30 Moutoukias, 1988.

31 Sobre las articulaciones viales entre España-Buenos Aires y Lima véase: Serrera, 1992, $165-176$. 
de Buenos Aires, ante la llegada sistemática de los navíos españoles y europeos. Caído el sistema de galeones y ferias en Portobelo, los navíos de registro se convirtieron hacia 1750 en el medio de transporte primordial para el tráfico imperial, siendo Buenos Aires no sólo el puerto preferido de los navíos europeos sino también el punto de escala privilegiada para las naves con destino a los puertos de Chile y Perú que surcaban el Cabo de Hornos. A una mayor dinámica y asiduidad que las lentas y pesadas travesías de los galeones, los navíos particulares mejoraron no sólo las técnicas de navegación náutica sino también las condiciones de las bodegas para el traslado y la conservación de las mercaderías que se enviaban hacia las Indias. ${ }^{32}$ Los navíos de registro cobran especial consideración para el caso de la importación de cerámica china por Buenos Aires.

\section{GRÁFICA 1}

SEDAS, TEJIDOS Y LOZA DE CHINA POR LA GOBERNACIÓN DE TUCUMÁN Y BUENOS AIRES, SIGLO XVIII

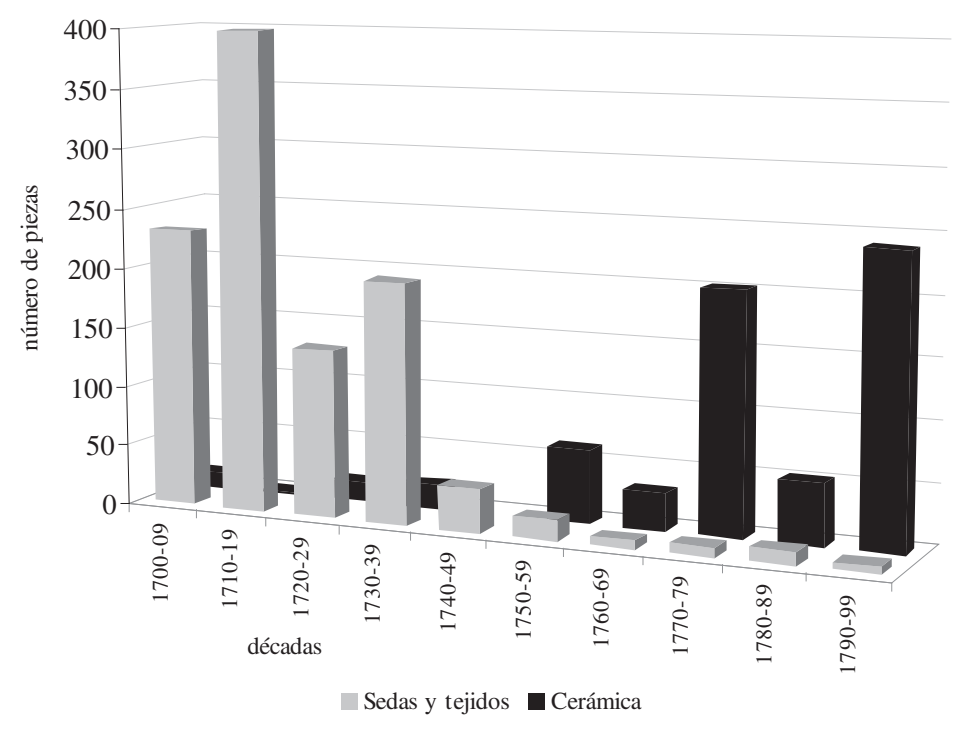

Fuente: Cuadro 2

32 García-Baquero, 1976, 163-175. 


\section{GRÁFICA 2}

SEDAS, TEJIDOS Y LOZA DE CHINA POR LA GOBERNACIÓN DE TUCUMÁN, SIGLO XVIII

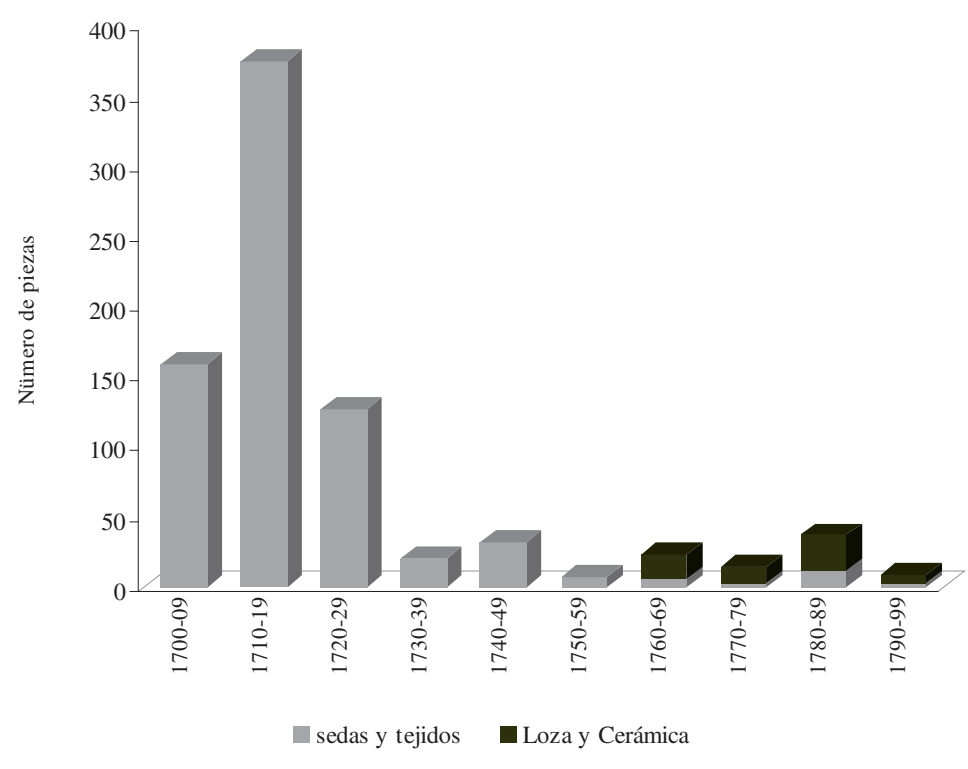

Fuente: Cuadro 2

A partir de la segunda mitad del siglo XVIII, con la apertura oficial de puertos y los nuevos cauces de comercio por el espacio trasatlántico, la naturaleza del movimiento y consumo de bienes chinos cambió radicalmente. Los estudios de Assadourian, Salas de Colama y, para el caso concreto de Córdoba, el de Arcondo acuerdan que el consumo de telas extranjeras europeas comenzó a ser más frecuente en los grupos sociales medios e inferiores. ${ }^{33}$ La oficialización del navío de registro como medio de transporte dominante por Buenos Aires, las ventajas de un comercio exterior más libre y menos gravoso permitieron una disminución de los precios de las mercancías extranjeras por el espacio sudamericano. Según Arcondo, para el caso de Córdoba, la tradicional indumentaria de ropa de la tierra (lienzos, cordellate y bayetas) con la que se vestían los mestizos habría sido sustituida a partir de 1750 por lienzos, bretañas, angaripolas y otros

33 Assadourian, 1982, 191-207; Salas de Coloma, 1998, II; Arcondo, 1992, 220-227. 
textiles europeos y orientales que presentaban ahora menores costos de producción y comercialización. ${ }^{34}$ Por su parte, Assadourian comparte la premisa de Arcondo, sosteniendo que el quiebre sucedió en la segunda mitad del siglo XVIII, cuando los tejidos ingleses invadieron los mercados masivos y populares que hasta entonces estaban reservados a lo producido por los obrajes locales. ¿Qué ocurre con el tejido oriental, aquel rubro que durante las primeras décadas del siglo aparecía con tanta frecuencia? Apoyados en los datos que brindan los inventarios, el textil de seda chino continuará ingresando al espacio, pero ya no tendrá aquella intensidad de la primera mitad de la centuria. Los inventarios dan cuenta de la gran «invasión» de tejidos europeos y de algodón de la India que con precios bastante módicos comienzan a desplazar al textil chino del mercado consumidor. Esto fue posible, en gran medida, por el proceso de mecanización que comenzaron a registrar por esas décadas las fábricas textiles europeas.

\section{GRÁFICA 3}

SEDAS, TEJIDOS Y LOZA DE CHINA POR BUENOS AIRES, SIGLO XVIII

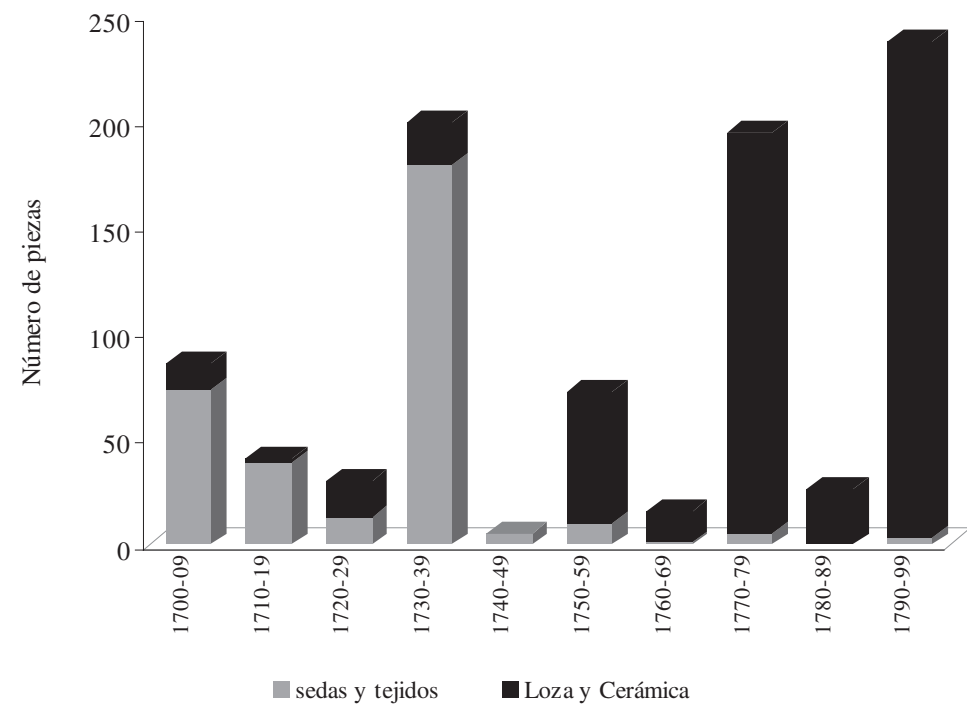

Fuente: Cuadro 2

34 Arcondo, 1992, 103-227. 
Miguel de Lastarria, secretario del virrey del Río de la Plata en los últimos años del siglo, se sorprendía de la abundante cantidad de artículos de China en la ciudad, donde «son muy apetecidos de los habitadores del virreinato de Buenos Aires quienes llaman de la China a todo objeto procedente de Asia». ${ }^{35}$ Cuando Lastarria hacía referencia al gran consumo de los objetos orientales pensaba, en particular, a la «loza de china»; artículo que figura en una gran cantidad de inventarios. Las gráficas 2 y 3 , apoyadas en los datos del cuadro 2, arrojan importante resultados. Comencemos por confirmar algunas hipótesis ya explicitadas desde una lectura cuantitativa, considerando la información de los más de 170 inventarios consultados. En páginas anteriores decíamos que el textil de China (elaborado o bruto) circuló y se consumió con mayor intensidad en los mercados de la gobernación de Tucumán que en Buenos Aires. Para el período 1700-1750, existían 713 textiles de China por la gobernación de Tucumán, mientras que para el caso de Buenos Aires identificamos menos de la mitad: 310. Esta diferencia se explicaría por el ya comentado funcionamiento del eje del Pacífico. En segundo lugar, resulta notoria en este primer período la escasez de loza china por ambos espacios, en particular por la región de Tucumán. Los contados casos se refieren a la región porteña -52 piezas-, donde la loza de China habría ingresado gracias al arribo o a las confiscaciones que las autoridades porteñas aplicaron sobre navíos extranjeros y españoles que llegaban a sus costas. Conocemos el caso ocurrido en 1719 a la fragata La Arbela donde las autoridades de Buenos Aires comisaron grandes cantidades de loza de China que había en su cargamento. ${ }^{36}$ Resulta curioso notar la escasa presencia de loza china por la ciudad de Córdoba y el Tucumán en esta primera parte del siglo, cuando los mercados de Lima, Guayaquil y zonas aledañas se veían importantes cantidades de porcelana china. ${ }^{37}$ Importantes estudios han puesto de manifiesto que este tipo de piezas chinas se consumieron durante toda la época colonial y por todo el Orbe Indiano: desde la Nueva España, pasando por Caracas, Cuenca, Quito, el Perú, Chile, hasta la región costera atlántica de Brasil ${ }^{38}$ ¿Cuál habría sido el motivo que desde el Perú no se reexpidiera la cerámica china hacia los mercados australes? Podría suponerse que la no movilización de la loza oriental desde Lima

35 Lastarria, 1977, 90.

36 Villalobos, 1968, 40.

37 Crespo, 2006, 312, 314, 315, 316, 319, 320, 327, 355, 356, 364 у 373.

38 Para el caso novohispano: Curiel, 1992, 141; en el caso del Perú y zonas del altiplano: Kuwayama, 2000-01 y 2009; Jamieson, 2003, 259; sobre Brasil, Amaral Lapa, 2000, 209. 
hacia la gobernación de Tucumán en la primera parte del siglo se explicara al peligro de exponer un bien tan frágil y vulnerable a los complicados medios de transporte y los trayectos terrestres por montañas.

Por el contrario, en el cuadro 2 y las gráficas siguientes salta a la vista que a partir de 1750 ocurrió un quiebre en lo que se refiere al comercio y consumo de bienes chinos por el espacio porteño y del interior. Considerando el período 1750-1799 encontramos 601 piezas de cerámica china (o su imitación europea) por el espacio porteño; mientras no superan las 60 piezas para la gobernación de Tucumán. Aquel auge del textil de China que se veía para la primera parte del siglo desaparece. Considerando el mismo período que va desde 1750 a 1799 sólo se identificaron 30 piezas textiles originales de China o copias europeas para la gobernación de Tucumán; mientras que tan sólo 19 en Buenos Aires. Es decir, a partir de la segunda parte del siglo comenzará a ser la loza de China el rubro dominante de las piezas asiáticas que circularon por Buenos Aires y las regiones que comprenderán, luego de 1776, el virreinato del Río de la Plata. ¿Qué tipo de loza china figuran en los inventarios? Primaron los objetos de utilidad culinaria, de cocina y mesa. Abundan las jícaras, tasas para té, para café o para caldo, cafeteras, pocillos o pozuelos, teteras, vinajeras, platos o platillos para dulce, fuentes, soperas, floreros, jarras, azucareras, tapaderas y poncheras.

Para comprender la aparición de la loza china por Buenos Aires es necesario aproximarnos, al menos brevemente, a la evolución de la producción de loza china. Entre mediados del siglo XVII y finales del XVIII China alcanzó un desarrollo técnico en la fabricación de loza inigualable. Claro está que Japón tenía una gran tradición en la actividad. La diferencia radicaba en que la loza japonesa siempre fue un trabajo de alta calificación artesanal, mientras que ahora, la cerámica china, tomaba la iniciativa para producir una imitación barata de la cerámica japonesa imari para los mercados de Europa y de América. ${ }^{39}$ La ciudad de Jingdezhen fue el complejo industrial más importante para su producción, con una mano de obra que alcanzaba los 100 mil alfareros. ${ }^{40} \mathrm{~A}$ fines del siglo XVII, entre la Compañía Holandesa de las Indias Orientales (VOC) y sus rivales europeas como la inglesa, francesa y dinamarquesa exportaron en su conjunto más de 70 millones de piezas de porcelana china desde la ciudad de Jingdezhen

39 Kuwayama, 2000-01 y 2009.

40 Feng y Shi, 2001. 
hacia el mercado europeo. ${ }^{41} \mathrm{~A}$ esta enorme cifra se le debería anexar los cargamentos de loza que traficó desde 1785 la Real Compañía de Filipinas cuyos barcos, además de las navegaciones por el Cabo de Buena Esperanza, realizaron numerosas escalas en Buenos Aires en el marco de los derroteros entre España-Cabo de Hornos-Filipinas. ${ }^{42}$ Es sabido que a principios del siglo XVIII ya existían en Europa varias fábricas que producían una imitación de la loza de China. De manera que, además de una parte de esa enorme cifra de loza original, desde Europa se reexpidieron copias de imitación de la loza china fabricadas en Holanda, Inglaterra y Francia hacia Buenos Aires ${ }^{43}$ Esto lo vamos a poder confirmar en el último apartado del ensayo, al abordar el ingreso de los llamados bienes chinescos. Por lo tanto, la loza original de China como su copia europea llegaron a Buenos Aires a través de los navíos de registro españoles y europeos. Buenos Aires y el interior del virreinato del Río de la Plata habrían sido las terminales de estos productos. Los trabajos de arqueología urbana dan muestras de una vida cotidiana donde la vajilla china era una de las lozas importadas más utilizadas en el Buenos Aires virreinal. ${ }^{44}$

Las mesas porteñas y de Córdoba exhibían ajuares producidos en diferentes latitudes del planeta. Las hubo de loza, como la de China, pero también vemos en los inventarios artículos de cristal, de peltre, de hojalata, de vidrio y de plata que llegaban desde España, Sajonia, Inglaterra, Holanda, Francia y Génova. También notamos la entrada de vajilla de Chile y de producción local, denominada comúnmente barro de la tierra. En el variopinto y globalizado mundo del comedor rioplatense, la vajilla de plata labrada era la favorita de los ricos, quienes las veían útiles por su resistencia y como símbolo de prestigio al exhibirlas en sus estantes. ${ }^{45}$ En 1769, un integrante del clero, sostenía que «la vajilla de loza y de peltre no la utilizan la gente de distinción [...] que prefieren una mediana vajilla de plata para el servicio de la mesa» ${ }^{46}$ No resulta casual ver en los inventarios que la vajilla de plata labrada superaba, con creces, los valores de la loza de China. En la última década del siglo una tipo de azucarera china podía costar, como precio máximo, los dos pesos cuando una de plata se cotizaba en

41 De Vries, 2009, 163.

42 García Regueiro, 1984, 27-30; Díaz-Trechuelo, 1965, 199.

43 Piénsese por ejemplo, en la cerámica holandesa Delft. Soboul, Lemarchand, Fogel, $1992,181$.

44 Senatore, 1995, 30; Norman, 2005-2006; Schávelzon, 2010.

45 Porro y Barbero, 1994, 3-107.

46 Probst, 1941, 440. 
63 pesos. Un plato de loza de China alcanzaba el valor de un peso mientras que los de plata rondaban los 8 y 28 pesos. ${ }^{47}$

Comparemos los hábitos de consumo entre la loza europea y la de China. El ajuar procedente de Sajonia y de Inglaterra, que vendría a despojar de la primacía adquirida por la loza de Sevilla durante la primera mitad del siglo, también llegó a las mesas de los hogares más acomodados del virreinato del Río de la Plata. Por su precio y calidad, la vajilla y cerámica fabricada en Occidente, particularmente la inglesa, no se destinó al amplio mercado consumidor de la región. Por el contrario, la loza de China ocupó uno de los menajes de procedencia extranjera de mayor consumo en las casas coloniales. Las razones de su amplio consumo fueron casi idénticas a las que permitieron el apogeo del textil asiático para la primera mitad del siglo. Vemos una vajilla oriental que, en términos de precio y calidad, alcanzó el mundo consumista de elite como los pedidos de un público consumidor amplio. Lo que ocurrió en las mesas de comedor de las familias de la Nueva España también habría ocurrido en las de Buenos Aires ${ }^{48}$ El consumo de la loza de china en un extenso arco social podría comprobarse al notar que un juego de café de loza china -integrado por la tetera, la cafetera, la azucarera, el jarrito para servir, los pocillos y platillos- podía costar desde 8 pesos hasta superar los $200 .^{49}$

En los protocolos de las familias pudientes de Córdoba y Buenos Aires se puede ver una lujosa porcelana proveniente de China. Tomemos el caso de uno de los más poderosos comerciantes de Buenos Aires, Manuel Escalada, quien fue regidor de la ciudad porteña en 1766. Sus relaciones comerciales con Cádiz le permitieron disponer un enorme depósito en el centro de Buenos Aires; un almacén que se utilizaba para reexpedir las mercaderías importadas por el puerto hacia el interior. Si bien el inventario de tienda de Manuel de Escalada apuntaba a un capital total de 100 mil pesos, el historiador Torre Revello descubrió que Escalada contaba con un capital de 500 mil pesos; el más elevado capital de toda la ciudad porteña. ${ }^{50}$ Disponía su casa para realizar ostentosas fiestas junto al virrey del Río de la Plata, Cevallos. En el convite exponía una finísima porcelana y loza de China y delicados juegos de plata. ${ }^{51}$ Pero lo asombroso es que la elegante

\footnotetext{
47 Porro y Barbero, 1994, 46.

48 Curiel, 1992, 132-137.

49 Porro, Astiz y Rospide, 1982, I, 185.

50 Torre Revello, 1927-28, 498-499.

51 Lesser, 2005, 49 y 108.
} 
vajilla asiática que ofrecía en su mesa no era la que disponía en el siguiente inventario:

cuatro tacitas para café de losa de la China; cajita con cuatro platos para dulce de losa de China; tres tasas para caldo de la China; tres cafeteras de la China; tres floreros de la China; siete platillos para dulce de la China; seis pocillos sin asas con sus platillos de la China; dieciséis pocillos de la China con asas; treinta y nueve tacitas para café de la China; treinta y nueve platillos de la China. ${ }^{52}$

Esta enorme colección de ajuar chino que Escalada poseía en su almacén fue clasificado en el inventario como loza vulgar y ordinaria; un calificativo que parece justificarse por la tasación total: «15 pesos por todo». ${ }^{53}$ Es posible suponer que esta loza no fuera la de uso personal ni tampoco la que exponía ante la presencia del virrey. Más bien, eran artículos disponibles para un público consumidor general de Buenos Aires y del interior. Un caso similar es el de Eugenio Lerdo de Tejada, quien fue compañero de Escalada en el cargo de regidor y en los emprendimientos mercantiles a gran escala con España. La loza china anotada en su inventario de tienda de 1791 era asombrosa por su variedad y abundancia: poseía, como ajuar de procedencia oriental, casi 240 platos y platillos de diferentes colores y diseños y más de 6 docenas de tazas y tacillas. ${ }^{54}$ Tejada emprendía la misma práctica de redistribución por las plazas interiores del Virreinato del Río de la Plata. La adquisición de la cerámica asiática por familias y vecinos comunes de Rosario, Córdoba o aún de remotas regiones rurales como San Pedro y Río Cuarto se confirma en varios de los protocolos notariales consultados. ${ }^{55}$ En 1772 en la partición de bienes por muerte de Catalina Drolet, mujer distinguida de la aristocracia porteña, se logra distinguir lo que era una loza fina de China ordinaria de la suntuosa. Poseía una cafetera de China de 12 pesos y otra que no alcanzaba el peso. ${ }^{56}$ La relación también podría hacerse con los utensilios de fabricación local. En 1783, el vecino de Buenos Aires Vicente Quinzy, manifestaba en su inventario loza de China, donde el plato estaba a un real y medio. Sin embargo, también

52 AGN, Ramo Sucesiones, 5563, s/n de exp., 104.

53 AGN, Ramo Sucesiones, 5673, s/n de exp., 376.

54 AGN, Ramo Sucesiones, 6727, s/n de exp., 4-8.

55 Francisco Javier Carranza vivía en San Pedro. En su inventario de 1795 aparecen «cinco pocillos de losa China a 3 reales cada uno», AGN, Ramo Sucesiones, 7707, s/n de exp., 16. El señor José de Maldonado, residente en Río Cuarto, presentaba en su inventario de 1774 «tres vasos de loza de China a cuatro reales cada uno», AHPC, Ramo Escribanía 1, 379, exp. 2, 44.

56 AGN, Sucesiones, 5560, exp. 6, 4-8. 
contaba con platos de peltre tazados cada uno a 2 reales, $1 / 2$ real más caro que el asiático. ${ }^{57}$

Una comparación entre la mínima tasación de cerámica china que figura en los protocolos con el ingreso de un jornal diario o mensual que tenían los trabajadores reforzaría la hipótesis de un consumo ampliado de los bienes chinos. Es cierto que la relación entre jornal y el valor inventariado no es una relación lineal de causa-efecto; pero no cabe duda de su íntima relación. De acuerdo a los protocolos notariales consultados, una docena «de tacitas con ramitos de China» alcanzaba los 7 reales; la docena de platos chinos blancos con azul y dorado iban desde los 7 reales a los 2 pesos; la jarra de losa sólo valía 1 real; una escupidera de China los 6 reales y una fuente rosada de China los 4 reales. ${ }^{58}$ Los trabajadores urbanos especializados de Buenos Aires habrían estado en condiciones de acceder a esta canasta de productos si tomamos en cuenta que el ingreso diario de un carpintero oscilaba entre los 8 y los 10 reales, el de albañil desde los 4 a los 8 reales, el de un herrero entre 6 y 8 reales y los calafates 18 reales diarios. ${ }^{59}$ Más aún, esos artículos habrían estado no sólo al alcance de un peón urbano no especializado que tenía un ingreso de 4 reales diarios, sino también del trabajador rural no especializado cuyo salario mensual era entre los 6 y los 7 pesos. ${ }^{60}$

\section{Las «mutaciones» de los bienes}

La periodización que advertimos sobre el ingreso de sedas, tejidos y cerámica china por los diferentes ejes mercantiles fue de la mano con el tipo de intervención a las que los productos fueron sometidos. En la primera mitad del siglo las telas chinas fueron sometidas a un proceso de «domesticación», incorporándoles estilos y diseños occidentales. Advertimos de una corriente cultural en la cual el objeto oriental era transformado con el propósito de llegar a su formato occidental. Por el contrario, la loza de China que ingresó por el Atlántico porteño fue intervenida para imitar modas del Oriente a raíz del gran éxito que estas tuvieron en décadas anteriores. Aquí vemos cómo un producto occidental fue intervenido en vistas de su «orientalización».

57 AGN, Sucesiones, 7773, exp. 3, 102.

58 Estos precios se desprenden de los inventarios de las referencias al cuadro 2.

59 Johnson, 1990.

60 Johnson, 1990; Mayo, 2004, 129. 
La mayoría de las telas Chinas se importaron en varas o piezas para su confección. Como lo expresa el cuadro 2, en el período de mayor auge del textil chino (1700-1739) el número de varas o piezas registrado en los protocolos fue de 752 mientras que los tejidos elaborados eran menos de la mitad: 234. Para Córdoba computamos 489 varas y 192 de artículos confeccionados, mientras que en Buenos Aires 263 y 42 respectivamente. Prácticamente, el $75 \%$ de la tela china que se consumía por el espacio llegó en vara o en piezas, listas para trabajarlas y decorarlas al gusto local. $\mathrm{La}$ presencia mayoritaria de seda bruta o sin confeccionar nos permite comprender las facilidades que tenía el producto para sortear la ley de prohibición de su circulación y consumo. Dos modalidades de elaboración se ejecutaban sobre la tela china bruta, no elaborada. Por un lado, la producción de un artículo elaborado en los obrajes locales utilizando el textil chino, como insumo; por el otro, el añadido al tejido propiamente occidental o local de la tela oriental, como función complementaria o accesoria. Resultó recurrente el consumo de tejidos fabricados y diseñados en Europa, España o en el Perú, en los cuales el elemento oriental o chino era sólo el forro de la vestimenta, sea para revestirla o para protegerla. El vestido de la doncella Jerónima de Saracho, hija del capitán José Hurtado de Saracho, residente en Córdoba consistía de «una tela rica de Sevilla forrado en Pequín colorado hasta su casaca y su botón de oro del Perú». ${ }^{11}$ En 1709, el capitán Antonio Guerrero residente en Buenos Aires registró en su inventario «una chupa de raso de Sevilla forrada en pequín musgo». ${ }^{62}$ Vemos aquí que a un tejido occidental se le anexaba tela china. La seda venida del Oriente también podía intervenirse en los talleres locales de teñido como bien se reflejaba en el inventario post-mortem de 1713 del mercader de Córdoba, Juan Solano Lafuente. Allí se anotaba « 24 varas de raso liso negro bazeteado [sic] teñido en Lima de la China»; o la de 1724 perteneciente al vecino de Buenos Aires Cristóbal Rendón en la cual se registraba « 20 varas y tercias de raso de la China teñido en esta ciudad». ${ }^{63}$ El tejido chino, a la vez, podía estar acompañado de otras telas de origen asiático, como el algodón de la India. En el patrimonio de 1748 de Domingo Carranza encontramos «una sobrecama de angaripola de la China a flores con forro de coleta de la India» tasada en 30 pesos. $^{64}$

61 AHPC, Ramo Protocolo, Registro 1, inventario 119, 23.

62 AGN, Ramo Sucesiones, 6246, exp. 3, 40-42.

63 AHPC, Ramo Escribanía 1, 231, exp. 7, 8-14.

64 AGN, Ramo Sucesiones, 5346, s/n de exp., 1v. 

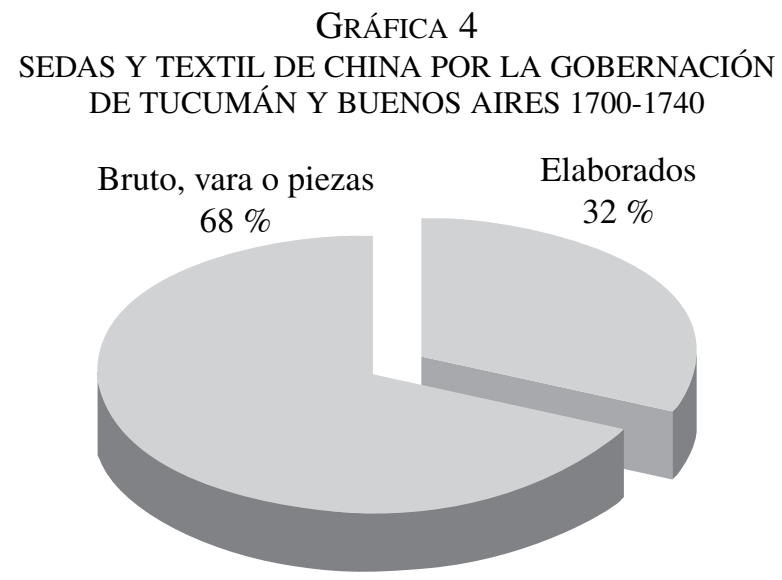

Fuente: Cuadro 2

El anexo de botones, plata y oro del Perú fueron las terminaciones más frecuentes que se les hacían a las telas orientales. Resultaban intervenciones sobre un artículo para adaptarlo al gusto del consumidor. En la ciudad de Santiago del Estero, perteneciente a la gobernación de Tucumán, el maestre de campo y encomendero José Díaz de Cáceres contaba en su testamento de 1703 «una chupa de raso de la China a flores con botonaduras y forrado en seda de la China más otra chupa con magas de brocato de la China y guarnecida con encajes de plata». ${ }^{65}$ En el patrimonio de 1704-1705 perteneciente a Catalina de Cabrera, viuda del capitán de la ciudad de Córdoba Francisco Suárez de Cabrera, figuraba «una pollera de gurbión de la China con tres vueltas de bandas de oro y plata» tasada en 50 pesos. ${ }^{66} \mathrm{En}$ la misma ciudad, el capitán Antonio de Cabrera exponía en su inventario «una chupa de raso de la China aforrada en tafetán nácar con mangos y botones y con flecos de plata» de 24 pesos. ${ }^{67}$ En la carta dotal de 1724 de Paula Carnero Carvallo, hija del capitán Cristóbal Carnero residente en la ciudad de Córdoba, aparecía «una pollera de damasco azul de la China con tres vueltas de sevillaneta [sic] de plata del Cuzco con su pestañuela de cinta colorada», cuyo valor alcanzaba los 53 pesos. ${ }^{68}$ En la ciudad de Salta, el

65 AHPC, Ramo Escribanía 1, 206, exp. 6, 13-14.

66 AHPC, Ramo Protocolo, Registro 1, inventario 98, s/n de fs.

67 AHPC, Ramo Escribanía 1, 218, exp. 4, 3.

68 AHPC, Ramo Protocolo, Registro 1, inventario 112, 250. 
capitán Bernardo Blanco Guerra sufrió en 1727 un embargo de bienes donde había dos chupas de china, una en raso y la otra en terciopelo, con botones de plata peruana. ${ }^{69}$ Por último, el capitán Bernardo de la Pascua, residente en la ciudad de Buenos Aires, anotaba en su testamento de1708 «una pollera de raso de la China musgo con puntas de plata» que rondaba 20 pesos. ${ }^{70}$ Los casos manifiestan que la inyección de diferentes elementos de plata encarecía la prenda asiática, logrando que el objeto tuviera una marcada exclusividad para los sectores privilegiados y de mayor adquisición. La cerámica china también sufrió una intervención para que el producto alcance un formato occidental. La jícara oriental, muy presente en los inventarios, era una especie de pozuelo fabricado en China sin asa para el consumo de chocolate, muy de moda en el Perú y la Nueva España. ${ }^{71} \mathrm{Si}$ bien con menor intensidad, el virreinato del Río de la Plata participó de esta transformación. En 1756, Pedro Cueli, residente en Buenos Aires, daba en sucesión una jícara de China para tomar chocolate. Las tacitas de loza china elaboradas originalmente para tomar y servir el té eran utilizadas para el consumo de chocolate o el café. ${ }^{72}$

En el último cuarto del siglo XVIII, aparece de manera recurrente en los protocolos el término chinesco para referirse a lozas y tejidos. Esta definición remitiría a piezas fabricadas en Europa que imitaban los diseños y estilos de los objetos chinos. La copia de lo oriental en los talleres textiles o de cerámica de Europa comenzó su auge en el primer cuarto del siglo XVIII, pero estas copias recién llegarán con fuerza al puerto de Buenos Aires en la segunda mitad de la centuria. Manuel de Escalada, ese gran mercader que tuvimos la oportunidad de mencionar en páginas anteriores, tenía en su inventario casi 100 docenas de abanicos chinescos que imitaban los abanicos originales de China. ${ }^{73}$ Los abanicos asiáticos fueron quizá el tercer tipo de mercadería oriental más frecuente llegados a la región. Los abanicos originales de China compuestos de marfil, tan necesarios para la coquetería de las mujeres distinguidas, tuvieron una presencia continua en el siglo pero en estas últimas décadas del siglo se vieron acompañados de copias europeas, como el «abanico de concha nácar nuevo estilo chinesco» que posee en 1782 el vecino porteño José Antonio Díaz Pimienta. ${ }^{74}$ Vemos

69 AHPC, Ramo Escribanía 1, 251, exp. 3, 131-133.

70 AGN, Ramo Sucesiones, 7701, s/n de exp., 17-18.

71 Curiel, 1992, 132-137; Jamieson, 2003, 272.

72 Porro, Astiz, Rospide, 1982, I, 22-24.

73 AGN, Ramo Sucesiones, 5673, s/n de exp., 3-234.

74 Porro y Barbero, 1994, 183. 
así que los bienes fabricados en una Europa que comenzaba a vivir transformaciones industriales profundas se «orientalizaban». Si en la primera mitad del siglo notábamos que el tejido procedente de China pasaba por el filtro de «occidentalización», ahora se afrontaba un proceso inverso, donde lo europeo se viste de lo chino.

En suma, el comercio y las pautas consumistas de los artículos chinos aquí analizados son una muestra por demás elocuente de los alcances que tuvo la mundialización comercial en la América colonial; un suceso similar a la revolución del consumo que se vivió por Europa en el siglo XVII. ${ }^{75}$ El fenómeno estudiado refleja la hegemonía que tenían de las fuerzas de la occidentalización. Es cierto que la cultura material colonial gozó de una escenografía muy diversa, con objetos procedentes de diferentes partes del mundo, pero toda esa riqueza material tendía a uniformizarse, a europeizarse. En otros términos, cualquier intento de diversidad que haya tenido la mundialización, Europa se ocupó de canalizarlo, «occidentalizando» lo chino $\mathrm{u}$ «orientalizando» lo europeo.

Recibido el 23 de diciembre de 2013

Aceptado el 12 de junio de 2014

\section{Bibliografía}

Álvarez de Abreu, Antonio José: Extracto Historial del Comercio entre China, Filipinas y Nueva España [1736]. Ed. de Carmen Yuste, México, Instituto Mexicano de Comercio Exterior, 1977, 2 v.

Arcondo, Aníbal: El ocaso de una sociedad estamental. Córdoba entre 1700-1760, Córdoba (Argentina), Universidad Nacional de Córdoba, 1992.

Assadourian, Carlos Sempat: El sistema de la economía colonial, Lima, Instituto de Estudios Peruanos, 1982.

Bernabéu, Salvador y Martínez Shaw, Carlos (eds.): Un océano de seda y plata: el universo económico del Galeón de Manila, Sevilla, Escuela de Estudios Hispano-Americanos, CSIC, 2013.

Bernal, Antonio Miguel: «La carrera del Pacífico: Filipinas en el sistema colonial de la carrera de Indias», en Cabrero, Leoncio (coord.), España y el Pacífico, Legazpi, I, Madrid, Sociedad Estatal de Conmemoraciones Culturales, 2004, 485-525.

Bonialian, Mariano: El Pacífico Hispanoamericano. Política y comercio asiático en el Imperio español (1680-1784), México, El Colegio de México, 2012.

75 McCants, 2007. 
Bonta de la Pezuela, María: Porcelana china de exportación para el mercado novohispano: la colección del Museo del Virreinato, México, Instituto de Investigaciones Estéticas, UNAM, 2008.

Borah, Woodrow: Comercio y navegación entre México y Perú en el siglo XVI, México, Instituto Mexicano de Comercio Exterior, 1975.

Céspedes del Castillo, Guillermo: Lima y Buenos Aires. Repercusiones económicas y políticas de la creación del virreinato del Plata, Sevilla, Escuela de Estudios Hispano-Americanos, 1947.

Chaunu, Pierre: Les Philippines et le Pacifique des Ibériques (XVI ${ }^{e}, \mathrm{XVII}^{e}, \mathrm{XVIII}^{c}$ siècles). Introduction méthodologique et indices d'activités, Paris, SEVPEN, 1960.

Concolorcorvo [seud.]: El Lazarillo de ciegos caminantes: desde Buenos Aires hasta Lima (1771-73), Buenos Aires, Espasa-Calpe, 1946.

Crespo Rodríguez, María Dolores: Arquitectura doméstica de la ciudad de los Reyes (1535-1750), Sevilla, Escuela de Estudios Hispano-Americanos, CSIC, 2006.

Curiel, Gustavo: «Consideraciones sobre el comercio de obras suntuarias en la Nueva España de los siglos XVII y XVIII», en Guadalupe Victoria, José; Vargas Lugo, Elisa y Uriarte, María Teresa (comps.), Regionalización en el Arte. Teoría y Praxis. Coloquio Internacional de Historia del Arte, Culiacán, Gobierno del Estado de Sinaloa, UNAM Instituto de Investigaciones Estéticas, 1992, 127-160.

Díaz-Trechuelo, María Lourdes: La Real Compañía de Filipinas, Sevilla, Escuela de Estudios Hispano-Americanos, CSIC, 1965.

Feng, Lingyu; Shi, Weimin y Gensheng, Chen: Perfiles de la cultura china, s. 1., China Intercontinental Press, 2001.

Flores, Ramiro: «El secreto encanto de Oriente. Comerciantes peruanos en la ruta transpacífica (1590-1610)», en O’Phelan Godoy, Scarlett y Salazar Soler, Carmen (eds.), Passeurs, mediadores culturales y agentes de la primera globalización en el mundo ibérico, siglos XVI-XIX, Lima, Pontificia Universidad Católica del Perú, 2005, 377-409.

García Regueiro, Ovidio: «Manila, Acapulco y Cádiz: Una concepción del comercio español con Oriente en el siglo XVIII», Cuadernos Hispanoamericanos, 409, Madrid, 1984, 4-34.

García-Baquero González, Antonio: Cádiz y el Atlántico (1717-1778), Sevilla, Escuela de Estudios Hispano-Americanos, 1976.

Jamieson, Ross William: De Tomebamba a Cuenca, arquitectura y arqueología colonial, Quito, Abya-Yala, 2003.

Johnson, Lyman: «Salarios, precios y costo de vida en el Buenos Aires colonial tardío», Boletín del Instituto de Historia Argentina y Americana Dr. Emilio Ravignani, 2, Buenos Aires, 1990, 133-157. 


\section{TEJIDOS Y CERÁMICA DE CHINA EN LA GOBERNACIÓN DE TUCUMÁN}

Kuwayama, George: «Cerámica China», Iconos, Revista Peruana de Conservación, Arte y Arqueología, 3, Lima, 2000-2001, 20-29.

Kuwayama, George: «Chinese Porcelain in the Viceroyalty of Peru», en Pierce, Donna and Otsuka, Ronald (ed.), Asia \& Spanish America. Trans-Pacific Artistic \& Cultural Exchange, 1500-1850, Denver, Mayer Center for Precolumbian \& Spanish Colonial Art at the Denver Art Museum, 2009, 165-174.

Lapa, José Roberto do Amaral: A Bahia e a Carreira da Índia, São Paulo, Editora Hucitec, UNICAMP, 2000.

Lastarria, Miguel: Portugueses y Brasileños hacia el Río de la Plata: un informe geopolítico (1816), Buenos Aires, Editorial Pool, 1977.

Lesser, Ricardo: La última llamarada. Cevallos, primer virrey del Río de la Plata, Buenos Aires, Biblos, 2005.

Malamud Rikles, Carlos: Cádiz y Saint Maló en el comercio colonial peruano (1698-1725), Jerez de la Frontera, Diputación de Cádiz, 1986.

Mayo, Carlos: Estancia y Sociedad en la Pampa (1740-1820), Buenos Aires, Biblos, 2004.

McCants, Anne: «Exotic Goods, Popular Consumption, and the Standard of Living: Thinking about Globalization in the Early Modern World», Journal of World History, 18-4, Honolulu, 2007, 433-462.

Moreyra Paz-Soldán, Manuel (comp.): El Tribunal del Consulado de Lima, Cuadernos de Juntas (1706-1720), Documentos para la historia económica del Virreinato del Perú, Lima, Lumen, 1956.

Moutoukias, Zacarías: Contrabando y control colonial en el siglo XVII: Buenos Aires, el Atlántico y el espacio peruano, Buenos Aires, Centro Editor de América Latina, 1988.

Navarro García, Luis: «El comercio interamericano por la mar del Sur en la edad moderna», Revista de Historia, 23, Caracas, 1965, 11-55.

Norman Weissel, Marcelo: «Arqueología de rescate de obra nueva del Banco Galicia. Testigos urbanos del ser occidental», Anales del Instituto de Arte Americano, 39-40, Buenos Aires, 2005-2006, 129-157.

Porro, Nelly Raquel y Barbero, Estela Rosa: Lo Suntuario en la vida cotidiana del Buenos Aires virreinal. De lo material a lo espiritual, Buenos Aires, PRHISCO-CONICET, 1994.

Porro, Nelly Raquel; Astiz, Juana Eloisa y Rospide, María Margarita: Aspectos de la vida cotidiana en el Buenos Aires virreinal, Buenos Aires, Universidad de Buenos Aires, 1982.

Probst, Juan: «El costo de la vida en Buenos Aires según una encuesta del año 1769», en Contribuciones para el estudio de la historia de América. Homenaje al Dr. Emilio Ravignani, Buenos Aires, Peuser, 1941, 431-442.

Ramos, Demetrio: Minería y comercio interprovincial en Hispanoamérica (siglos XVI, XVII y XVIII), Valladolid, Universidad de Valladolid, 1970. 
Richthofen, Ferdinand (Freiherr von): China. Ergebnisse Eigener Reisen, Berlín, D. Reimer, 1877-1905.

Salas de Coloma, Miriam: Estructura colonial del poder español en el Perú. Huamanga (Ayacucho) a través de sus obrajes, siglos XVI-XVIII, Lima, Pontificia Universidad Católica del Perú, 1998, 3 v.

Schávelzon, Daniel: «La cerámica histórica europea en la cuenca del Plata: notas sobre Santa Fe la Vieja», en Jornadas de Antropología de la Cuenca del Plata, II, Arqueología, Rosario, Escuela de Antropología de la Facultad de Humanidades y Artes de la Universidad Nacional de Rosario, 2010, 196-200.

Schenone, Héctor; Gori, Iris y Barbieri, Sergio: Patrimonio artístico Nacional, inventario de bienes muebles, Provincia de Jujuy, Buenos Aires, Academia Nacional de Bellas Artes, 1991.

Schurz, William Lytle: «Mexico, Peru and the Manila Galleon», Hispanic American Historical Review, 1-4, Durham, 1918, 389-402

Schurz, William Lytle: The Manila Galleon, New York, E. P. Dutton \& Co., 1939.

Senatore, María Ximena: Tecnologías nativas y estrategias de ocupación española en el Río de la Plata, Columbia, University of South Carolina Press, 1995.

Serrera Contreras, Ramón María: Tráfico terrestre y red vial en las Indias Españolas, Barcelona, Lunwerg Editores, 1992.

Soboul, Albert; Lemarchand, Guy y Fogel, Michele: El Siglo de las Luces. Los inicios (1715-1750), I, Madrid, Akal, 1992.

Solá Miguel Ángel: «La Hacienda de San Francisco de Xavi, 1785», Anales del Instituto de Arte Americano, 10, Buenos Aires, 1957, 47-93.

Villalobos, Sergio: El comercio y la crisis colonial: un mito de la independencia, Santiago, Universidad de Chile, 1968.

Vries, Jan de: La Revolución industriosa. Consumo y economía doméstica desde 1650 hasta el presente, Barcelona, Crítica, 2009.

Yuste, Carmen: El comercio de la Nueva España con Filipinas 1570-1785, México, Instituto Nacional de Antropología e Historia, 1984.

Yuste, Carmen: Emporios transpacíficos. Comerciantes mexicanos en Manila 1710-1815, México, Universidad Nacional Autónoma de México, 2007. 